\title{
Methodological proposal for assessment and adaptation in oil industry plants in Brazil's coastland
}

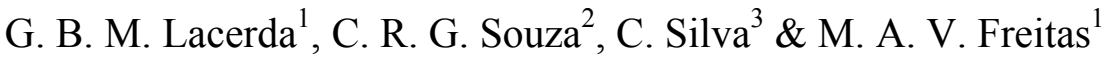 \\ ${ }^{I}$ Program of Energy and Environmental Planning, Coordinated \\ Postgraduate Engineering Program, \\ Federal University of Rio de Janeiro, Brazil \\ ${ }^{2}$ Postgraduate Program of the Department of Geography, \\ University of São Paulo, Brazil \\ ${ }^{3}$ Program of Civil Engineering, Coordinated Postgraduate Engineering \\ Program, Federal University of Rio de Janeiro, Brazil
}

\begin{abstract}
This work presents a methodological proposal for medium-term integrated planning and management of extreme natural risks and technological risks, focusing on events of coastal flooding caused by sea level rise (SLR). The research site contemplates private oil industry facilities, located in Redonda Island, Guanabara Bay, Rio de Janeiro, Brazil.

Guanabara Bay suffers interaction with extra-tropical cyclones in the South Atlantic, where disasters, floods and coastal erosion need to be foreseen and managed properly. Under extreme meteorological-oceanographic conditions, a framework of predictive systems for risk management that involves climatic and environmental issues promoting greater capacity and responsiveness are necessary.

In Brazil, the work is justified by the lack of methodological tools ad hoc for assessment and adaptation of coastal structures to face global change vulnerabilities, making them resilient and integrated into the natural coastal systems, and also to the emergency and responsiveness public and corporate systems' plans and programs.

Using software ArcGIS 9.3, simulation scenarios of sea level elevation and flooding impacts were elaborated, whose boundary conditions considered the
\end{abstract}


predictions of the IPCC (Intergovernmental Panel on Climate Change), Stern Report, in addition to the syzygy tides and storm surges that occurs in the bay.

The development of the methodology culminated in: the assessment of vulnerabilities of the industrial infrastructures; prior knowledge of flooding from altimetry tracks; the estimation of losses and costs due to physical property damage; the elaboration of thematic maps of adaptive measures and proposed structural interventions to decision making; and the need to prepare a regulatory framework to ensure integration with the plans and programs of public and enterprise systems.

The application of the methodology can ensure the continuity of the company's activities to some level of flooding on the island, or to promote the search for new alternatives of production, storage and logistics.

Keywords: climatic vulnerabilities, assessment, adaptation, methodological proposal, response actions, simulation of scenarios, thematic maps, decision making.

\section{Introduction}

IPCC (Intergovernmental Panel on Climate Change) [5, 6] have published reports that stipulate sea level elevation up to $1 \mathrm{~m}$ (meter) till the end of this century. Tide gauge measurements performed in the north coast of the Indian Ocean confirm these predictions, as well as the tendency to rise that has been accelerating since 1870 , which currently reaches static sea level elevation values ranging from 1 to $2 \mathrm{~mm} /$ year. In their studies for up to 100 years, Church et al. [2] and Rohling et al. [13] point out that sea level rise can reach $1.60 \mathrm{~m}$.

Lacerda et al. [8] cite that, with the predictable increase in sea level, it is possible to presume the occurrence of great physical and financial losses: infrastructures can become vulnerable and collapse; coastland constructions will disappear; seaports will be destroyed; populations and commercial and industrial installations will have to be relocated; public and private sewage and drainage systems will be affected; new hurricanes could reach the country's southsoutheast coast; rainstorms even more intense will punish cities with great social and political impacts over populations in risk areas and; higher and extreme temperatures in short time periods, as well as more diseases, will be registered.

In Brazil, private and public policies on integrated coastal impact management over industrial structures incorporating evaluation elements and structural and non-structural adaptive interventions that have an environmental issue of natural hazards and the institutional integration of technological risks as cross sections to the problem of coastal flooding are still incipient.

For this purpose, an ad hoc instrumental methodology was developed, aiming for an evaluation and adaptation in a diagnostic, prognostic and management context for prevention and reduction of damages arising out of the probability of occurrence of potential flood risks in coastal oil plants. In this work, an integration of information and the rigging of defence and meteorological systems and of plans, programs and emergency systems and actions to existing responses and others to be developed, both corporate and public, are contemplated. 


\section{Objectives and work pre-viability}

The situation or event that overcomes local capacity, causing great hazard, destruction and human suffering and which needs external help is defined by ISDR [3] as disaster. Disasters are classified in 3 groups: hydro-meteorological, geophysical and biological, in which, in accordance to Tucci [16], can cause flooding, draught, impacts on human health, landslides, avalanches and hunger. So forth, natural disasters are earthquakes, floods, tsunamis, etc. Human disasters are those manmade, such as wars. Technological disasters are those derived from accidents involving chemical substances, or dangerous equipment. Considering the actual and future possibility of higher magnitude and frequency on the occurrence extreme natural flood disasters on coastal oil plants, there could happen a conjugation of a natural disaster with a technological, on behalf of installation flooding causing ruptures, leakages, contamination, explosions, harm to the labor force, interruption of supply, environmental fines, among others.

In the point of view of Lacerda and Andrade [7], the management of disasters implies in the development of strategies of actions relative to the governance of extreme natural and technological risks, that consist in the existence of adequate and efficient public policies in the identification of risks through diagnosis, prognosis and management, and in the development of knowhow on risk factor reduction in addition to the preparation for effective response and recuperation.

The main objective of this research consists in the search for answers to the following questions: 1) How to evaluate and know the probable hazards to the vulnerabilities encountered? 2) How to plan to meet the necessary adaptations? 3) Which adaptive ad hoc measures on the island will be taken? 4) Considering that the properties (or assets) of the island must be protected, how to provide its utilities and assure industrial activity till certain level of flooding?

The relevance and innovation of this research relates to the application of a broader methodological proposal than the current studies. An estimated evaluation of the percentage of losses and damage costs, highlighting the need for further studies for preparation of ad hoc thematic maps that point out adaptive measures with a structural intervention proposition was developed. The results of the methodological proposal can be applied in densely populated or strategic coastal sites situated in vulnerable marine flooding regions.

This research presents pre-viability because it considers: a) projections of global occurrence of weather events becoming more intense and frequent, with regional and local consequences; b) the promotion of resilient cities and sites, providing their adaptations to global climate change; c) the need for medium and long term integrated planning and management, to meet the frequent new demands in monitoring and response to flood catastrophe and hazards, with direct relation to projections and events arising from sea level rise; d) early development of adaptive methodological tools predictive to climate change and vulnerabilities resulting from sea level rise in coastal areas for public and / or private managers and decision makers. 


\section{Characterization of the study area - Redonda Island and Guanabara Bay}

The building installations and oil sector infrastructures are located in both coastline and islands in a region of Guanabara Bay in the State of Rio de Janeiro. In this area, the existing emergency and technological risk management programs, as well as medium and long term development plans, do not contemplate environmental risk governance on global climate change, whose effects include local and regional scales.

The research site, Redonda Island, contextualizes the geographic and thematic study by presenting features of flood probability by sea level rise, and by its strategic relevance in regional energy supply. In Rio de Janeiro, situated in Guanabara Bay, the Redonda Island Waterway Terminal (figure 1) and "Ilha d'Água" form together an industrial plant projected for a daily production of 14 million $\mathrm{m}^{3}$ of different types of oil and gas products.

In figure 1, Redonda's Island existing infrastructure is also presented, as well as a flood simulation inferred from altimeter tracks related to sea level rising from $1.40 \mathrm{~m}$ to $19.00 \mathrm{~m}$.

Figure 2 presents an updated panoramic view of the island.

The basic fact that supports the location of the oil industry in Guanabara Bay alleged by TRANSPETRO (marine transport enterprise of Petrobras - Brazilian

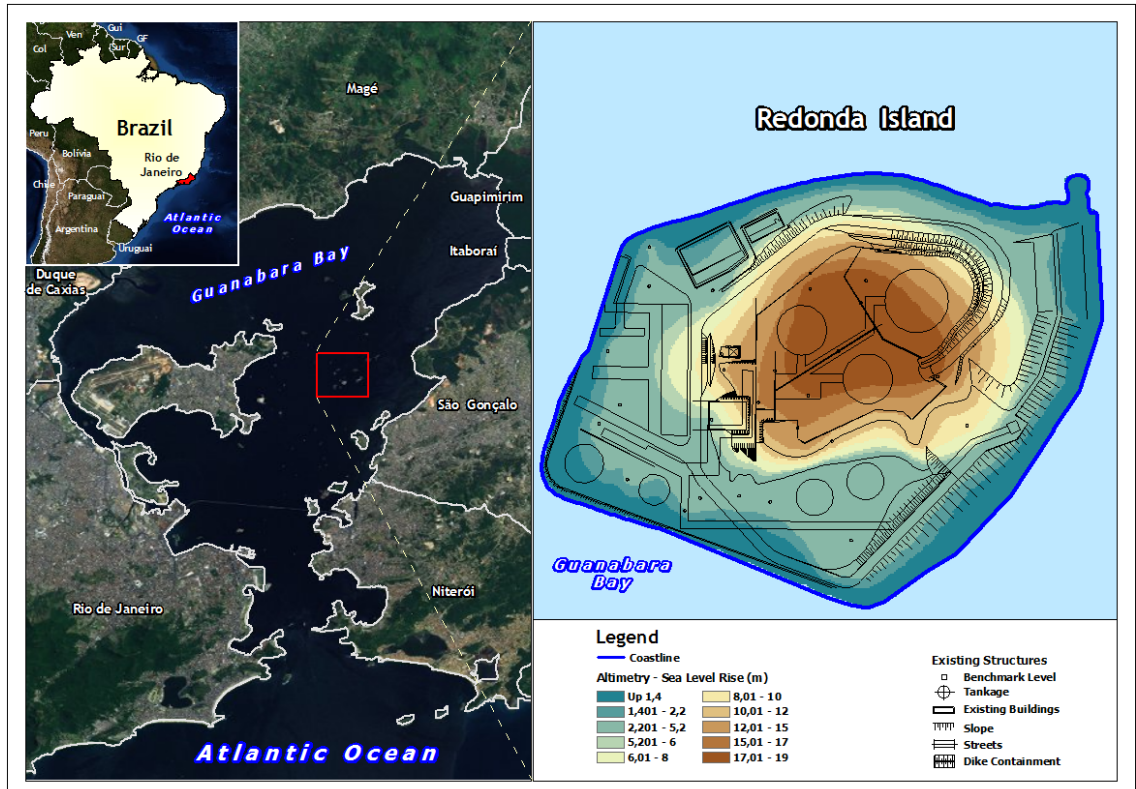

Figure 1: Localization of the study area: Guanabara Bay and Redonda Island, presenting its existing infra-structure and flood simulation by altimeter tracks under rising sea level. 


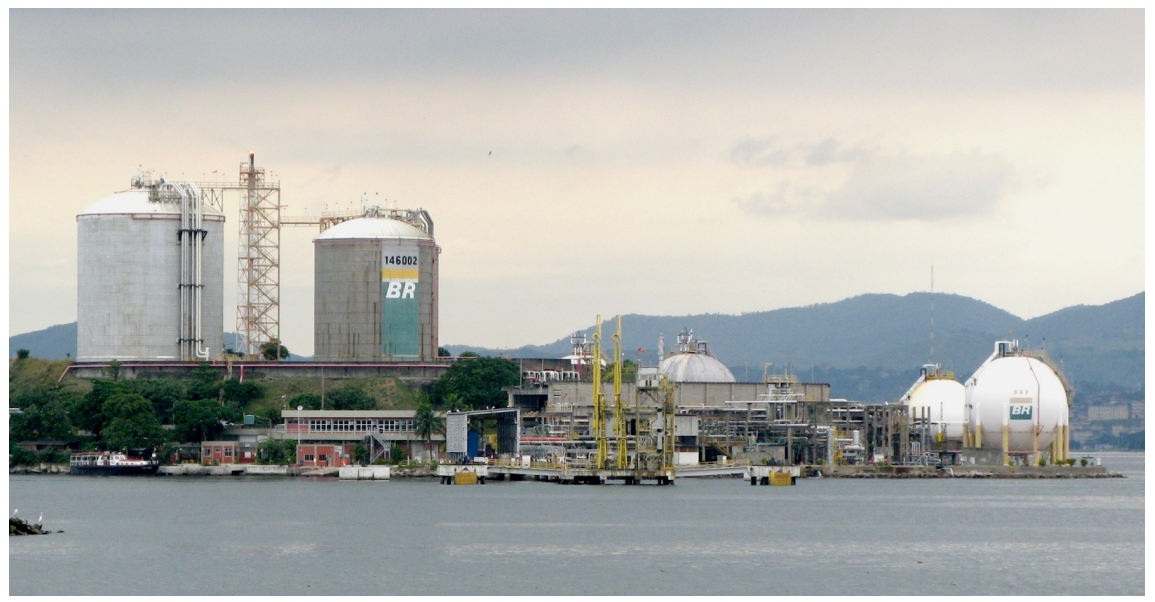

Figure 2: $\quad$ Redonda island terminal.

oil company) is the logistic readiness that the area offers for the transportation of liquefied natural gas stoked in Redonda Island and "Ilhas D'Agua", through a net of gas pipelines set in the Southeast region of Brazil.

Considering the coastal occupation in Rio de Janeiro City and its delimited shoreline, it is necessary to preview critical scenarios and elaborate legal normative instruments to all vulnerable regions - state and municipal, with the establishment of vulnerable climatic zones, adaptive and mitigation measures (structural and non structural) with definition of criteria and terms for occupation and/or evacuation, as well as to ensure the continuity of the island's activities with the least possible socio-environmental, financial and corporative impacts.

In accordance with different sources [1, 10, 14], there are various peculiar characteristics in Guanabara Bay. It is located in the southeastern region of Brazil (Latitude $22^{\circ} 48^{\prime} 12.70^{\prime \prime} \mathrm{S}$; Longitude $43^{\circ} 7^{\prime} 5.62^{\prime \prime} \mathrm{O}$ ), and has an extension of $380 \mathrm{~km}^{2}$ and is composed of a number of 30 islands and formed by sedimentary plains that incorporates various rivers and has an approximate population of 7.6 million in the surrounding area. The tides have a small and irregular amplitude with a maximum of $1.40 \mathrm{~m}$, average syzygy tide of $1.20 \mathrm{~m}$, average square of $0.80 \mathrm{~m}$ and minimum amplitude of $0.20 \mathrm{~m}$. The sea level elevation can vary from year to year, with approximate cycles of 20 to 30 years and oscillations of amplitude from $0.10 \mathrm{~m}$ to $0.50 \mathrm{~m}$ depending on site and season.

The influence of meteorological tides causes a natural increase in sea level, along with the approach of large waves and storm surge produced by extra tropical cyclones in the South Atlantic, can make the Metropolitan Region of Rio de Janeiro more vulnerable with the occurrence of tragedies and disorders for the population.

Variations associated to climatic events (meteorological tides) have been registered, whose differences between maximum and minimum values can reach $0.90 \mathrm{~m}$. Storm surges last in average 5 days in Rio de Janeiro's shoreline. Meteorological tides have been more frequent each time and waves can reach 
$4.5 \mathrm{~m}$. Extreme rainfall events from storm systems associated with the displacement of cold fronts cause precipitations of great intensity and higher frequency, like the ones that occurred in April of 2010 in Rio de Janeiro City, with precipitations of $323 \mathrm{~mm}$ in a period of 24 hours causing 233 deaths, 3.000 homeless and 11.000 displaced. In January of 2011, in the mountain region of Rio de Janeiro, precipitations reached $222 \mathrm{~mm}$ in 12 hours, causing 900 deaths, more than 9 thousand homeless and 11 thousand displaced.

The region, embedded between sea and mountains, has a topography that favors flooding and with the effects of a large rainfall, it becomes predictable. In this way, the gravity of the problems varies in function of the storm intensity and of the measures that will be adopted - prevention, hazard reduction and monitoring. The municipal Civil Defense disposes of 2 monitoring systems and of predictive actions for storms that could lead to floods, landslides and destruction: the Alerta Rio (a system that integrates state and local response agencies) and the Operations Center GEO RIO - municipal foundation that manages the slopes of the city. This foundation has installed sirens in some mapped risk areas and uses weather radar capable of detecting thunderstorms 48 hours in advance.

\section{Methodological proposal for assessment and adaptation for sea level elevation in coastland oil industry plants}

Lieber and Romano Lieber [9] define risk as not being a mere calculation of probability, but a social construction appropriate for the exercise of power, that dictates what is dangerous or not. Risks point out expectations of occurrence of involuntary events, uncertain and hazardous. Its analysis only makes sense if there is a probability of loss. Natural risks are those which are perceived and accepted by a social group or individuals subject to a possible action of a physical progress. Technological risk is defined as the potential occurrence of harmful events to life, as a result of investment decisions in the production structure. Industrial risks, in turn, are intended to clarify two basic components: the estimated frequency of accidental events in the industries and their potential consequences, which latter factor links risk analysis to the emergency response system, standing as an element of impact reduction.

Varnes [17] considers that an adapted concept of analysis and assessment of Risk (R) involves 3 phases: identification of the peril $(\mathrm{H}=$ Hazard $)$; assessment of the degree of exposure to danger or degree of incapacity to deal with the consequences of danger ( $\mathrm{V}=$ Vulnerabilities); and evaluation of response to danger or element at risk $(\mathrm{E}=$ Element ay risk $)$, that may depend on the resistance (ability to avoid environmental disturbances) and resilience (ability to respond to the consequences of environmental disturbances), such that $\mathrm{R}=\mathrm{H}$. V. E. In this perspective, the climate vulnerability can be defined as the degree of susceptibility of individuals or systems, inability to respond to the adverse effects of climate change, including climate variability and extreme events.

According to the IPCC [6], adaptation in the context of climate change is the adjustment of the natural, social and economic systems in response to the current 
and future climate stimulus and / or its impacts, in which may be adverse (damage) or beneficial (opportunities). Such a concept of adaptation is an approach that requires the integration and mainstreaming at all levels of decision making in different institutional levels: internal to the institution, between the different sectors of institutions, and between the institution and other sectors of society.

Werner and Smith [18] analyze that in situations of risk, being resilient is not to be invulnerable, which is not to say that in other circumstances the individual would not subdue. Otherwise, it is the capacity to rebuild after being struck, to adapt positively to what has been imposed, drawing experience from difficult situations, enriching in a unique way the experience and then use that learning to reverse the situation in your favor. The term "resilience" has been used as the capacity to face, overcome and be strengthened or transformed by experiences of adversity. This term brings into discussion the issue of governance in an institutional dimension and the social, economic, political and cultural limits of anthropogenic adaptation to ecosystem alterations. For the IPCC [4], a resilient city is the one that developed systems and skills to be able to absorb future shocks and still maintain essentially the same function, structure, systems and identity, getting ready to mitigate consequences of tensions and future shocks. The best way to deal with the problem of climatic vulnerability is to learn to cope and adapt to them (Lacerda et al. [8]). Thus, when subjected to shocks and stress, a city or site becomes resilient when they have the ability to adapt and recover, and while maintaining its functions, should also have the ability to make less troublesome future vulnerabilities.

The studies in the development of the methodological proposal ad hoc were divided in 3 distinct phases: diagnostic, prognostic and management. Initially, we started with the identification and preliminary assessment of the physical vulnerabilities of the site. For the prior knowledge of flooding by altimetric tracks, scenarios were developed using the ArcGIS 9.3 software, totalizing three different simulation scenarios of sea level rise and its impacts, with boundary conditions pre-established from data prediction of the IPCC (UN), the Stern Review [15], and measurements of syzygy tides and meteorological tides in Guanabara Bay. After that, it was possible to perform an analysis of flood risk

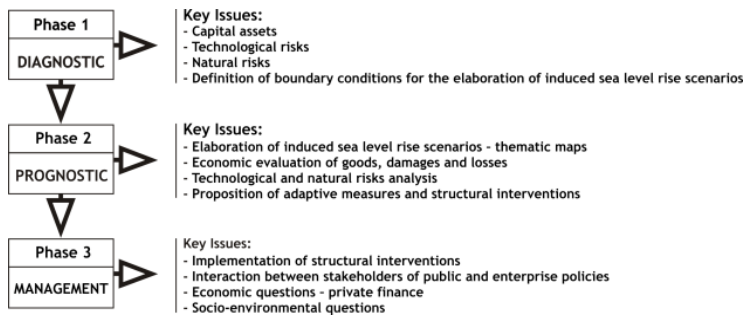

Figure 3: General flowchart - structure and levels of the actions of assessment management and adaptive measures. 


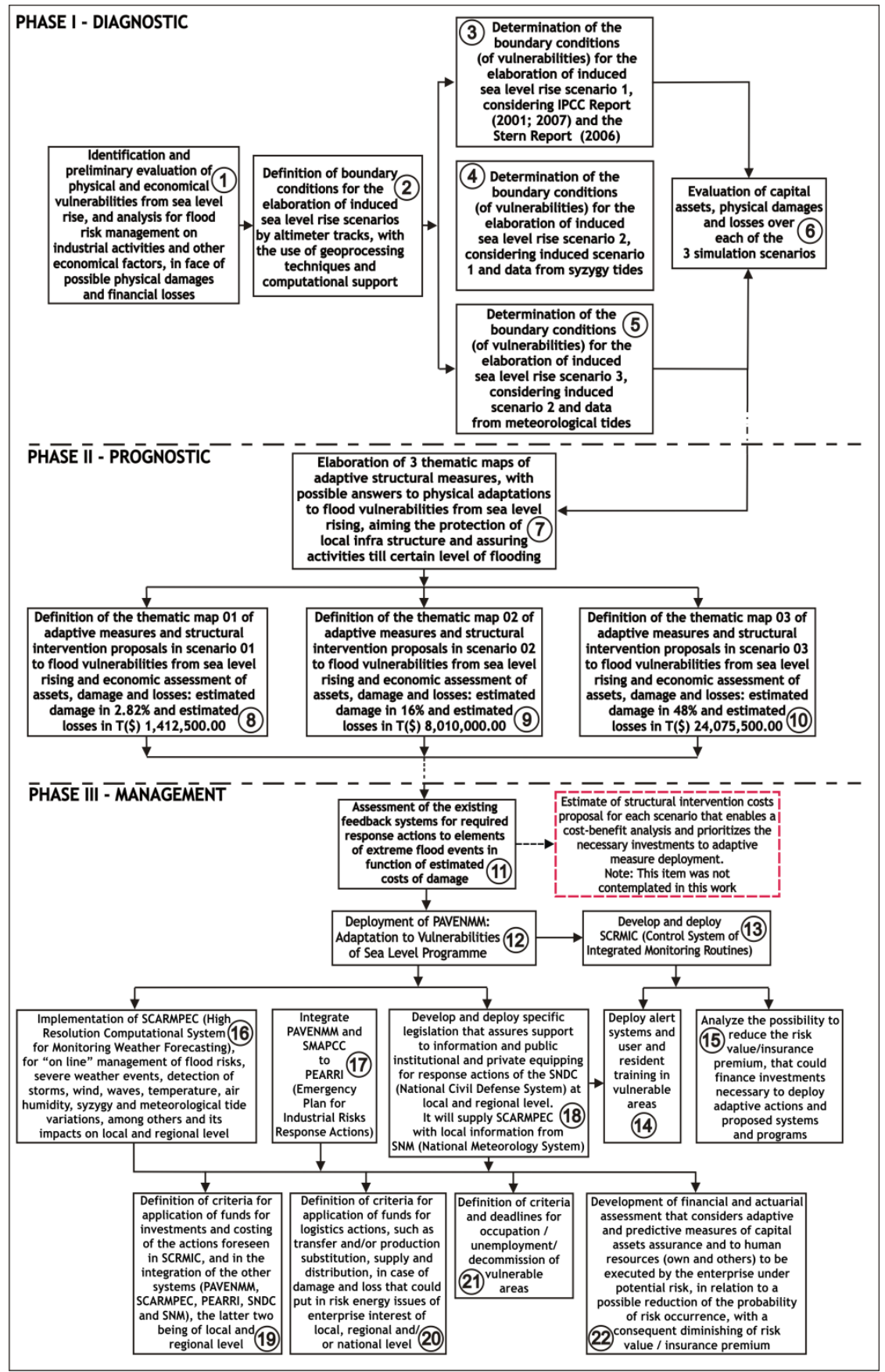

Figure 4: Flowchart of development of the methodology for assessment and adaptation of industrial oil plants. 
management on industrial activities, from an economic viewpoint of potential hazard physical loss and property damage. The perception of the need to develop studies to estimate costs for implementation of adaptive measures of structural interventions proposals points to the ongoing research.

Two flowcharts relative to the methodological approach proposal are presented bellow, figures 3 and 4, shown as development board block diagrams.

\section{Adaptation and management of extreme natural and technological risks}

Besides the evaluation of the technical, meteorological and oceanographic conditions on the research site, additional studies are suggested for structural actions adaptations not only for better understanding of the problem, but for better design solutions. Future studies should cover the estimated costs of the works of adaptive measures and proposed interventions to reduce or avoid losses in the physical facilities, as well as being supported by specific legislation to ensure the integration of all systems, plans and programs cited in the proposed methodology. About the management of extreme natural and technological risks, the PAVENMM has a bias integrator and encapsulates the plans, programs and emergency response systems to be developed and existing. The isolated management of PAVENMM will not ensure the necessary effectiveness and outcomes. As an example of the progress of the work herein suggested, in figure 5 the 3 rd scenario is presented, considered the most critical, with the proposition of adaptive structural measures, corresponding to that described in Box 10 of the figure 4.

Table 1 shows, in an arbitrary currency named Tupi (\$), estimated value of heritage property, estimated value of the damage, estimated percentage of the physical losses.

Table 1: Estimated values corresponding to good, damage and physical losses.

\begin{tabular}{|c|c|c|c|}
\hline Scenario & $\begin{array}{c}\text { Total Estimated Value } \\
\text { of Goods (T\$) }\end{array}$ & $\begin{array}{c}\text { Total Estimated Value } \\
\text { of Damage (T\$) }\end{array}$ & $\begin{array}{c}\text { Estimated Percentage } \\
\text { of Physical Losses }\end{array}$ \\
\hline III & $50.105 .000,00$ & $24.075 .500,00$ & $48,00 \%$ \\
\hline
\end{tabular}

To reduce or prevent losses in the physical facilities of the plant, this paper proposes the implementation of structural measures proposed in drawings in type of croquis. To date it has not been possible to estimate in the present work, the cost of works and proposed interventions to evaluate the cost-effectiveness.

\subsection{Scenario III}

In this third scenario, the occurrence of an extreme natural event was considered beyond the events of sea water elevation, estimated in IPCC and Stern reports, and the syzygy tide. This extreme event was a $3 \mathrm{~m}$ high wave which entered 
Guanabara Bay in April of 2008, and was considered a rare event. However, similar marine disturbances occurred in October of 2008, confirming the higher frequency of this extreme event. In this case, sea water elevation can go up more than $5 \mathrm{~m}$, making today's use of the island unfeasible.

This scenario may need the adoption of more complex measures which will demand more specific studies by the company that owns the island since estimated loss percentage is $48.00 \%$ and the total amount of damage is valued in $\mathrm{R} \$ 24,075,500.00$, and also because the only part of the island above sea level will be from elevation quota 9.00 to 19.00. The implementations of some measures to reduce or avoid losses in the physical facilities of the plant are suggested for scenario III, as follows (see Figure 5):

1. Protection and lifting of slopes of the eastern part of the island;

2. Protection of the other sectors of the island with conventional concrete walls (profile L) $5.50 \mathrm{~m}$ high;

3. Creation of 2 drainage wells in the island for pumping rain water (if the drainage system of the island is flooded);

4. Forecast of a system of drainage sluices to prevent flooding of the island;

5. Lifting of public area (i.e., streets, sidewalks) in the south and west of the island (for concurrent event of heavy rain);

6. Forecast deployment of FPSO (Floating Production, Storage and Offloading) structures sheltered in breakwaters, for non interruption of existing processes on the island, such as loading and unloading of gas;

7. Creation of breakwater structure in " $\mathrm{L}$ " to protect the island and give shelter for FPSO vessels.

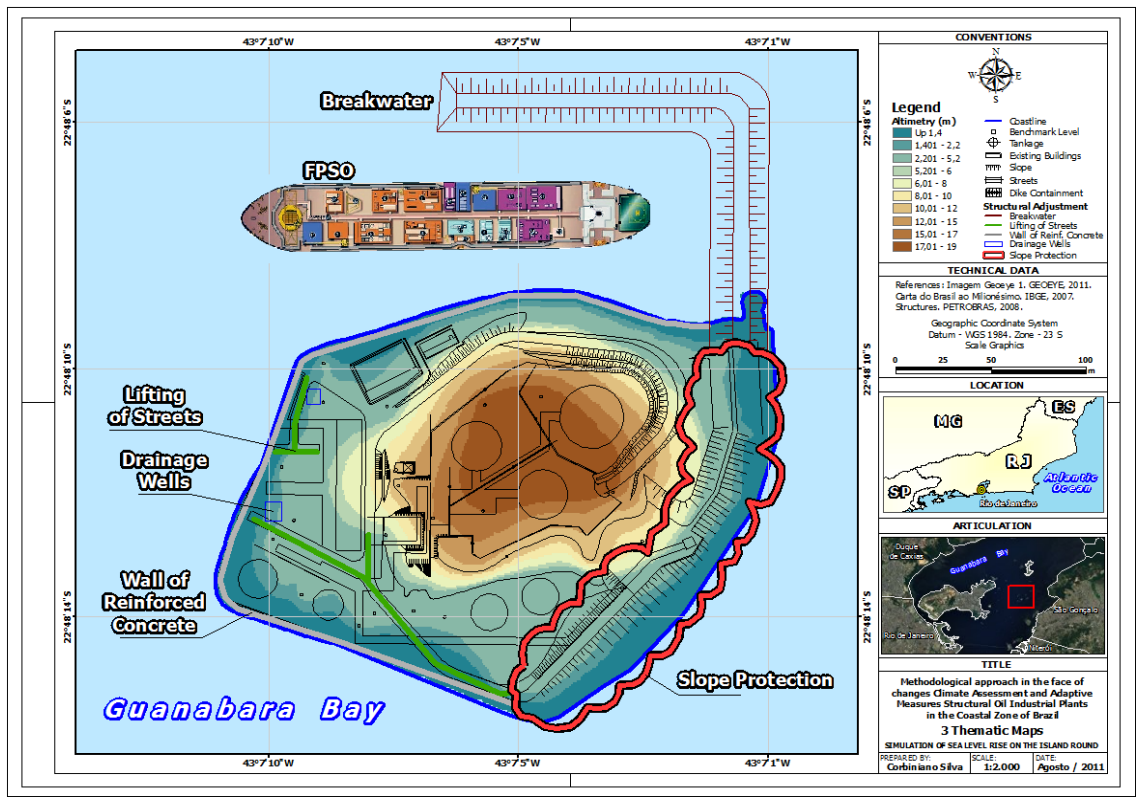

Figure 5: $\quad$ Proposed interventions in scenario III. 
Scenario III: Simulation of sea level elevation in Redonda Island, considering syzygy tide, analyzed reports and the occurrence of extreme natural events.

\section{Conclusions and recommendations}

Ripley [12] emphasizes that with the increase in catastrophic evidences and events, the importance of transforming common folk in better survivors stands out. Having in mind that you should not trust being lucky, and that in the middle of a crisis it is too late to learn lessons: part of the resources designated to security, plans, programs, politics for calamities and reactions must also contemplate participation and training of social agents and the population at risk.

The lack of clear and unequivocal knowledge systems about environmental problems as major issues underlying the growing social perceptions of risks makes them more socially problematic and intolerable. Coastal real estate prices will probably be one of the first economic indicators to reflect the rise in sea level, where investments in beach properties will be most affected.

In the case study of Round Island, it is assumed that the proposed methodology should address, in a more restrictive form, an analysis under the criteria of cost and benefit. In case the enterprise owner decides to protect their assets and extend their usefulness to the point of securing the industrial activities at the site till a certain level of flooding, it should have resources to spare to implement measures necessary for physical adaptations to the island, obtained in future studies, which could effectively mean introducing the environmental variable in the integral management of industrial risks in the plant. In order to reduce climate vulnerability and consequent risks to populations and activities, and integrate these criteria into PAVNMM, a more effective local legislation must consider the change in zoning for the purpose of land use planning and the types of activities allowed in densely populated urban areas, also covering other areas of expansion, metropolitan and micro-regions through Master Plans. In Brazil, the approach on flood risk management, despite being the subject of several important studies, is not contemplated in the National Policy for Water Resources - Law 9433/97 [11], and disregards a regulation in order to position decision makers at all stages: (1) pre-event actions of prevention and protection, (2) actions during the event, for protection and aid, (3) actions post-event of area recovery activity and rehabilitation, (4) mitigation, parallel to the others, which consists of risk management and loss reduction policies. This legislation must provide for and regulate the decommissioning of industries or other activities under potential risk in vulnerable regions which could cause socio-environmental damage, hazards on logistic supply and tourism, among others.

Omitting preventive actions without studying, evaluating and predicting adaptive ad hoc measures, establishing their risks and their mitigation solutions and responses to emergencies can constitute in loss of material and of human lives. Economic losses arising from recovery of structures, environmental fines, recovery of degraded areas, replacement of supply by business interruption, claims for damage to property, to human lives and to the image of the company owner may also be significant. The reduction in the likelihood of risk and the 
consequent reduction of insurance premium would also be affected. Insurance companies may suggest that the adjustment measures to vulnerabilities be implemented in areas under potential risk of flooding.

\section{References}

[1] Amador, E. S., 1997. Baía de Guanabara e Ecossistemas Periféricos: Homem e Natureza. Rio de Janeiro: E. S. Amador, 1997.

[2] Church, J., Gregory, J., Huybrechts, P., Kuhn, M., Lambeck, K., Nhuan, M.T., Qin, D., Woodworth, P., 2001. Understanding 20th century sea-level rise and projections for the future. Alfred-Wegener-Institut für Polar- und Meeresforschung e PIC - Electronic Publication Information Center.

[3] ISDR (International Estrategy for Disaster Reduction). Terminology: basic terms of disaster risk reduction. (revisão de 31/03/2004). Disponível em: http://unisdr.org/eng/library/lib-terminology-eng-p.htm

[4] IPCC, 1994. Working Group II Report - "Impacts, Adaptations and Mitigation of Climate Change: Scientific-Technical Analyses", Contribution of Working Group II to the Second Assessment Report of the Intergovernmental Panel on Climate Change.

[5] IPCC, 2001. Climate Change, The Scientific Basis, Cambridge Univ. Press, pp.881

[6] IPPC, 2007. Climate Change 2007: The Physical Science Basis - A report of Working Group I of the Intergovernmental Panel on Climate Change Summary for Policymakers. p.18, Cambridge University Press, Cambridge, United Kingdom and New York, NY, USA. IPCC, 2007. AR 4, Climate Change 2007: Impacts, Adaptation and Vulnerability, Contribution of Working Group II to the Fourth Assessment Report of the Intergovernmental Panel on Climate Change.

[7] Lacerda, G., Andrade, E. 2009. Mudanças climáticas e Análise de Risco da Indústria de Petróleo no Litoral Brasileiro. Fundación Mapfre, Madrid.

[8] Lacerda, G., Mamede, E., Assad, L., Freitas, M., 2010. Hydrological Vulnerabilities from Sea Level Instability: Physical Action Adaptation and Risk Management. Storm Surges Congress 2010. University of Hamburg, Germany.

[9] Lieber, R. R.; Romano Lieber, N. S.. O conceito de risco: Janus reinventado. In:Minayo, M.C.S.; Miranda, A.C. Saúde e ambiente sustentável: estreitando os nós. Rio de Janeiro: Ed. Fiocruz/Abrasco, 2002. p.69-111.

[10] Neves, C., Muehe, D., 2008. Impactos Possíveis da Elevação do Nível do Mar e Eventos Climáticos - RIO PROXIMOS 100 ANOS - O aquecimento global e a cidade. Prefeitura da cidade do Rio de Janeiro - Secretária Municipal de Urbanismo - Instituto Municipal de Urbanismo Pereira Passos, 2008.

[11] POLÍTÍCA NACIONAL DE RECURSOS HÍDRICOS, Lei 9433/1997.

[12] Ripley, A., 2008. Impensável: Como e por que as pessoas sobrevivem a desastres. São Paulo: Globo. 
[13] Rohling, E.J.; Grant, K.; Hemleben, C.H.; Siddall, M.; Hoogakker, B. A. A.; Bolshaw, M. and Kucera, M., 2007. High rates of sea-level rise during the last interglacial period. Nature Geoscience (published online in 16/12/2007, doi:10.1038/ngeo.2007.28).

[14] Santos, C., Silva, Maria., Salvador, Marcus., 2004. Dinâmica Sazonal e os Efeitos das Ressacas nas Praias de Niterói/RJ. Revista Brasileira de Geociências.

[15] Stern, N., 2006. Stern Review. The Economics of Climate Change. UK, p.267.

[16] Tucci, Carlos., 2007. Inundações Urbanas. - Porto Alegre: ABRH/RHAMA.

[17] Varnes, D. J., 1984. Landslide Hazard Zonation: Review of Principles and Practice. Paris: UNESCO Press, p.56.

[18] Werner, E., Smith, R., 1982. Vulnerable but invincible: a longitudinal study of resilient children and youth. New York: MacGraw-Hill. 